\title{
CEREBROVASCULAR REACTIVITY IN PRETERM INFANTS MEASURED BY NEAR- INFRARED SPECTROSCOPY AND TRANSCRANIAL CEREBRAL DOPPLER - A PILOT STUDY
}

\author{
S. Mitra ${ }^{1}$, H. O'Reilly ${ }^{1}$, M. Czosnyka ${ }^{2}$, P. Smielewski ${ }^{2}$, T. Austin ${ }^{1}$ \\ ${ }^{1}$ Neonatal Unit, ${ }^{2}$ Department of Academic Neurosurgery, Cambridge University Hospitals NHS Foundation \\ Trust, Cambridge, UK
}

Background: The characteristics of cerebral autoregulation and the ideal range of systemic blood pressure in preterm infants remain unclear. Transcranial Ccerebral Doppler (TCD) ${ }^{1}$ and near infra-red spectroscopy $(\mathrm{NIRS})^{2}$ are established techniques for the assessment of cerebral blood flow velocity (Fv) and cerebral oxygenation respectively.

\begin{abstract}
Aim: To study the correlation between a dynamic index of cerebral autoregulation, assessed using TCD, with indices obtained using NIRS in preterm infants and using these parameters, study the feasibility of determining the optimal MABP in individual infants.
\end{abstract}

Methods: Twelve preterm infants (mean gestation 26.5 weeks) were studied over eighteen episodes ( 2 hours each) within median 3days(range 1-9 days)of life. ICM+ software ${ }^{4}$ was used to collect and analyse data from NIRO 200NX and DWL Doppler system as well as the physiological variables from the intensive care monitors. Using this data, mean flow index $(\mathrm{Mx})^{2}$, total haemoglobin reactivity $(\mathrm{THx})^{3}$ and tissue oxygenation index of dynamic autoregulation $(\mathrm{TOx})^{2}$ were calculated as autoregulation indices.

Results: Coherence analysis of tissue oxygenation index (TOI), total haemoglobin index (THI)and Fv was above 0.6 in ultralow frequency. TOx and THx correlated with $\mathrm{Mx}[(\mathrm{R}=0.47, \mathrm{p}=0.057)$ and $(\mathrm{R}=0.59$, $\mathrm{p}=0.011)$ respectively] across individual recordings. 'Optimal MABP' was demonstrated in some individual recordings using $\mathrm{Mxopt}^{3}$ and TOxopt ${ }^{3}$.

Conclusion: This is the first study assessing the indices of dynamic monitoring of cerebral autoregulation in preterm infants. Initial results suggest that NIRS derived cerebrovascular reactivity indices (THx, TOx) correlate well with Doppler derived index $(\mathrm{Mx})$, and a non-invasive assessment of 'optimal MABP' is feasible in this population group. 